\title{
Dissolution of aluminium from sub-standard utensils under high fluoride stress: a possible risk factor for chronic renal failure in the North-Central Province
}

\author{
O.A.Ileperuma ${ }^{1 *}$, H.A. Dharmagunawardhane ${ }^{2}$ and K.P.R.P Herath ${ }^{1}$ \\ ${ }^{I}$ Department of Chemistry, Faculty of Science, University of Peradeniya, Peradeniya. \\ ${ }^{2}$ Department of Geology, Faculty of Science, University of Peradeniya, Peradeniya.
}

\begin{abstract}
Chronic renal failure of an endemic nature and unknown aetiology affects people in the North-Central Province of Sri Lanka. People affected, consume fluoride rich water and almost exclusively use sub-standard aluminium pots for cooking and storing water. Leaching of aluminium under different fluoride stress and under the acidic conditions used in cooking was studied. Aluminium was determined using a graphite furnace Atomic Absorption Spectrophotometer. In the absence of acidic spices, the amount of aluminium leached was quite small with a maximum of $1.20 \mathrm{ppm}$ reached after $10 \mathrm{~min}$ of boiling in $6 \mathrm{ppm}$ fluoride solution. However, under acidic conditions obtained during the use of tamarind at a $\mathrm{pH}$ of 3.02, the aluminium leached was around $18 \mathrm{ppm}$ even in the absence of fluoride with a regular enhancement of leaching at higher fluoride levels. The aluminium leached at $6 \mathrm{ppm}$ fluoride reached 29 ppm after 10 min of boiling. Similarly, at a pH of 2.12 in the presence of $0.1 \mathrm{M}$ tartaric acid, the maximum aluminium concentration leached reached ca. $50 \mathrm{ppm}$. Aluminofluoride complexes may play a significant role in causing chronic renal failure.
\end{abstract}

Keywords: Aluminium leaching, fluoride, groundwater, renal failure.

\section{INTRODUCTION}

In recent years, Chronic Renal Failure (CRF) of an endemic nature of unknown aetiology has been reported from the North-Central Province of Sri Lanka resulting in an increased rate of mortality ${ }^{1}$. Admission of CRF patients to the main hospital in this province has been increasing by about 3\% every year since 1996 and presently this accounts for $27 \%$ of all patients admitted. In the Medawachchiya area alone, $4.8 \%$ of the total population suffer from CRF. Clinical investigations ${ }^{1}$ have established that this condition cannot be attributed to hypertension or diabetes, two of the common causes of end stage kidney failure.

One striking geo-environmental factor in the affected geographical area is the high fluoride content in drinking water sources and almost all the reported CRF cases are from the fluoride rich areas. Most of the wells are of the dug well type, with occasional tube wells also used to obtain water for drinking and cooking. The fluoride content is highly variable but most fall within the range of 1-4 ppm although in some isolated cases this reaches values as high as $6 \mathrm{ppm}^{2}$. The affected area is in the dry zone with an average day time temperature of $34-38{ }^{\circ} \mathrm{C}$ and on an average the farmers drink about 2-3 litres of water daily to quench their thirst, resulting in the intake of 3-10 mg of fluoride daily.

Acute fluoride poisoning of experimental animals with effects on the kidneys $\mathrm{s}^{3,4}$ have been reported. Fluoride at micromolar concentrations inhibits phosphotase and this affects the endothelium of the affected arterioles and glomeruli ${ }^{5}$. The kidney appears to be the main target of fluoride toxicity affecting renal tissue and causing renal dysfunction.

The dissolution of aluminium in the presence of fluoride ${ }^{6-8}$ and complexing agents such as citric acid in fruit juices ${ }^{9}$ has been reported. The above studies have used aluminium pots which are properly anodized. The effects of complexing agents are expected to be more severe on inferior quality aluminium pots which are not anodized to give a protective layer of aluminium oxide and also contain many other impurity metals. People in 
the areas affected by CRF generally use such inferior quality aluminum pots. These aluminium pots and pans are made from the remelted scrap aluminium and used aluminium containing alloys, and hence are likely to be contaminated with other heavy metals such as lead which is a potent poison to kidneys. Such impurities present in the utensils could accelerate the dissolution of metal, when subjected to specially acidic conditions obtained during cooking ${ }^{10,11}$. Aluminium and fluoride in combination exerts a profound influence on human health than when present alone. Cocktails of $\mathrm{AlF}_{3}$ given at such low concentrations of $0.5 \mathrm{ppm}$ were found to cause Alzheimer like symptoms in rats and their premature deaths have been attributed to kidney failure ${ }^{12}$.

The objectives of this study were to determine the role of fluoride in the leaching of aluminium from cooking utensils under the typical cooking conditions and to assess the intake of fluoride to the body through all possible ways.

\section{METHODS AND MATERIALS}

Elemental composition of 4 samples with 2 samples each from 2 different used pots were analysed by X-ray fluorescence (Oxford ED2000) and Inductively Coupled Plasma (ICP) spectrophotometry (Perkin Elmer Optima, 3300DV, Trace metals laboratory, Department of Health and Mental Hygiene, Maryland, USA). Standard fluoride solutions were prepared using $\mathrm{NaF}$ (Aldrich, $>99 \%$ purity). A piece of a used aluminium pot weighing $2.7 \mathrm{~g}$ with a surface area of $1932 \mathrm{~mm}^{2}$ was used for all experiments. This was boiled in $250 \mathrm{~mL}$ of water containing different fluoride concentrations from 1-6 ppm for a $10 \mathrm{~min}$ period. The aluminium concentrations in the resulting solutions were determined using an Atomic

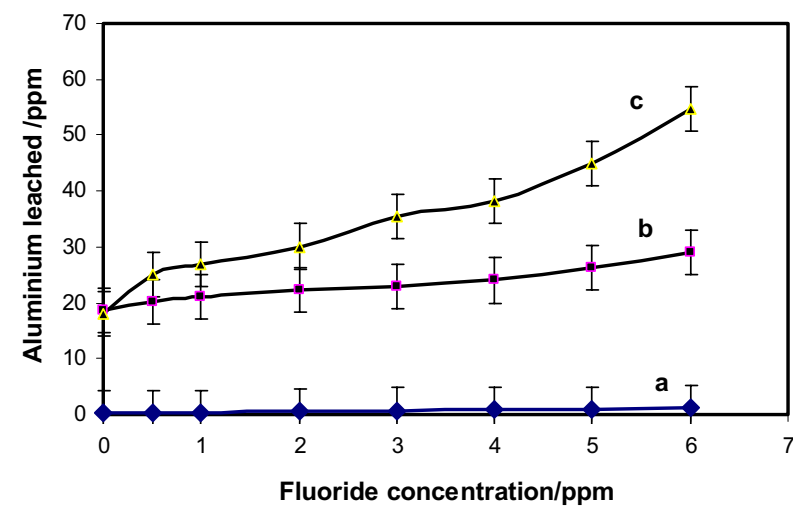

Figure 1: Aluminium leached under different fluoride stress; (a) deionised water (b) tamarind (c) tartaric acid.
Absorption Spectrophotometer with a graphite furnace (Perkin Elmer, Analyst-100 with Perkin Elmer model HGA 850 graphite furnace) and AS800 autosampler. In order to mimic typical cooking conditions where acidic spices such as tamarind are used, a solution containing $7.5 \mathrm{~g}$ of tamarind in $1 \mathrm{~L}$ of water was used. Similarly, aluminium leaching was studied in $0.1 \mathrm{M}$ tartaric acid solutions since this is the main acid present in tamarind. All determinations were carried out in triplicate.

\section{RESULTS}

\section{Analytical data on cooking pots and pans}

The sub-standard aluminum pots used by people in the affected area are locally fabricated by melting scrap aluminum and often alloys containing aluminum. Four samples with 2 samples each from 2 different used pots were analysed using X-ray fluorescence spectrophotometry and ICP, and there was a wide variation in the compositions of individual samples. These results are given in Table 1, where samples 1 \& 2 were from one pot while samples $3 \& 4$ were from a different pot. Samples 1 and 2 were the results of XRF analysis while samples $3 \& 4$ were from ICP spectrometry. It is clear that the pot from where samples $3 \& 4$ were taken had a higher aluminium content compared to the other pot. In order to compare the results from different experiments, pieces from the same pot were used for leaching experiments in different media.

\section{Aluminium leaching from cooking utensils at different fluoride concentrations}

Figure 1 shows the leaching of aluminium under different fluoride concentrations in the three media employed; deionised water (a) tamarind (b) and tartaric acid (c). A regular increase of aluminium leached is observed with increasing fluoride concentrations for all three media. In the deionised water medium, the aluminium leached was quite low reaching around $1.2 \mathrm{ppm}$ at the highest fluoride concentration of $6.0 \mathrm{ppm}$. In tamarind solution, which had a $\mathrm{pH}$ of 3.0, the concentration of aluminium leached was about $25 \mathrm{ppm}$ at a fluoride concentration of $6.0 \mathrm{ppm}$ while in $0.1 \mathrm{M}$ tartaric acid solution which had a $\mathrm{pH}$ of 2.12, aluminium leached reached $56 \mathrm{ppm}$ at the same fluoride concentration. It is also evident from Figure 1 that acidity of the medium plays a major role in the leaching of aluminium where the aluminum leached even in the absence of fluoride was around $18 \mathrm{ppm}$. 


\section{DISCUSSION}

The dissolution of aluminium in the presence of fluoride is a subject which has attracted attention of many researchers. The study carried out by Varner et al. ${ }^{12}$ postulates that at a fluoride concentration of $2 \mathrm{ppm}$ the predominant species involved are $\mathrm{AlF}_{3}$ and $\mathrm{AlF}_{4}^{-}$which penetrate the blood-brain barrier. A similar mechanism may help to explain the toxicity of these species to the kidney since it also involves the transport of aluminofluorides across biological membranes. Therefore, it is reasonable to assume that these complexes have greater permeability through biological membranes compared to the two species, aluminium and fluoride operating individually. Thus, it is important to study the speciation of aluminium in the presence of various fluoride levels and the following section gives a simplified analysis of the various aluminofluoride complexes formed. The equilibria involved are as follows;

$$
\begin{aligned}
& \mathrm{Al}^{3+}+\mathrm{F}^{-} \rightarrow \mathrm{AlF}^{2+} \\
& \mathrm{AlF}^{2+}+\mathrm{F}^{-} \rightarrow \mathrm{AlF}_{2}^{+} \\
& \mathrm{AlF}_{2}^{+}+\mathrm{F}^{-} \rightarrow \mathrm{AlF}_{3} \\
& \mathrm{AlF}_{3}+\mathrm{F}^{-} \rightarrow \mathrm{AlF}_{4}^{-} \\
& \mathrm{AlF}_{4}{ }^{-}+\mathrm{F}^{-} \rightarrow \mathrm{AlF}_{5}^{2-} \\
& \mathrm{AlF}_{5}^{2-}+\mathrm{F}^{-} \rightarrow \mathrm{AlF}_{6}^{3-}
\end{aligned}
$$

Table 1: Analytical results of used aluminium pots (samples $1 \& 2$ are from the same $\mathrm{Al}$ pot while samples $3 \& 4$ are from a different pot)

\begin{tabular}{crrrc}
\hline Element & Sample 1 & Sample 2 & Sample 3 & Sample 4 \\
\hline $\mathrm{Al}$ & 87.8 & 88.2 & 92.8 & 92.5 \\
$\mathrm{Zn}$ & 3.4 & 3.2 & 1.5 & 1.6 \\
$\mathrm{Fe}$ & 2.2 & 2.0 & 0.9 & 1.0 \\
$\mathrm{Cu}$ & 2.0 & 2.0 & 1.2 & 1.1 \\
$\mathrm{Si}$ & 1.9 & 2.1 & 1.2 & 1.4 \\
$\mathrm{~Pb}$ & 1.5 & 1.5 & 0.8 & 0.9 \\
$\mathrm{Mn}$ & 0.9 & 0.8 & 0.5 & 0.4 \\
\hline
\end{tabular}

Table 2: Percentage of Al-F containing species at different fluoride concentrations

\begin{tabular}{crrrc}
\hline $\mathrm{F}^{-}(\mathrm{ppm})$ & $\mathrm{AlF}^{2+}$ & $\mathrm{AlF}_{2}^{+}$ & $\mathrm{AlF}_{3}$ & $\mathrm{AlF}_{4}^{-}$ \\
\hline 1 & 11.6 & 63.9 & 23.7 & 0.7 \\
2 & 4.8 & 53.2 & 39.6 & 2.2 \\
3 & 2.7 & 43.9 & 49.1 & 4.3 \\
4 & 1.7 & 37.2 & 54.7 & 6.3 \\
5 & 1.1 & 31.6 & 58.8 & 8.5 \\
6 & 0.8 & 27.3 & 61.1 & 10.6 \\
\hline
\end{tabular}

The fraction of each of these aluminofluoride complexes can be calculated from the known stepwise formation constants of these complexes. These values used ${ }^{13}$ in our calculations were $\mathrm{K}_{1}=10^{6.13}, \mathrm{~K}_{2}=10^{5.02}, \mathrm{~K}_{3}=10^{3.85}$, $\mathrm{K}_{4}=10^{2.74}, \mathrm{~K}_{5}=10^{1.63}$ and $\mathrm{K}_{6}=10^{0.47}$. Calculations showed that the formation of $\mathrm{AlF}_{5}{ }^{2-}$ and $\mathrm{AlF}_{6}{ }^{3-}$ species under the fluoride concentrations employed are negligible and hence the concentrations of only the first four species in the above equilibrium reactions were calculated. At a fluoride concentration of $1 \mathrm{ppm}$, the species which predominate in solution are $\mathrm{AlF}^{+}, \mathrm{AlF}_{2}^{+}$and $\mathrm{AlF}_{3}$ accounting for over $98 \%$ of all aluminium containing species (Table 2). At higher fluoride concentrations the progressive increases in the concentrations of the $\mathrm{AlF}_{3}^{+}$ and the $\mathrm{AlF}_{4}$ species were observed.

In a study to assess the role of aluminium in the development of Alzheimer's disease ${ }^{12}$ where $0.5 \mathrm{ppm}$ aluminium fluoride in drinking water given to rats, it was found that the mortality rates were higher at this low concentration of aluminium fluoride than at higher concentrations. Furthermore, aluminium containing deposits were found in the kidneys of animals upon postmortem examinations and the role of aluminofluoride complexes in the transport of aluminium has been proposed.

Dissolution of aluminium in the presence of fluoride from cooking utensils has been reported in many studies. It was found that the concentrations of aluminium leached after $30 \mathrm{~min}$ of boiling from Al-Mn alloy were $2.0 \mathrm{ppm}$ and $3.0 \mathrm{ppm}$ in the absence and presence of fluoride ${ }^{7}$, whereas the same concentrations were increased to $8.0 \mathrm{ppm}$ and $16.8 \mathrm{ppm}$ in utensils made out of Al-Pb alloy. Similar results were obtained by Zolaly ${ }^{8}$ where up to $30 \mathrm{ppm}$ of aluminium was leached at a $\mathrm{pH}$ of 2.0 and a fluoride concentration of $1.0 \mathrm{ppm}$. Our results of aluminium leached under similar conditions in $0.1 \mathrm{M}$ tartaric acid solution and a $\mathrm{pH}$ of 2.12 were quite similar.

One important factor which should be taken into consideration in evaluating the health effects of fluoride is the total fluoride intake rather than the actual fluoride concentration in water. The WHO standard for fluoride in water is $1.0 \mathrm{ppm}$, which is typically the level of fluoride in municipal supplies where water is fluoridated. It implies that, on the average, a person drinks about $1 \mathrm{~L}$ of water a day so that the intake of fluoride should not exceed $1 \mathrm{mg}$ per day. However, this is not a reasonable standard for tropical countries where people consume up to 3 litres of water, specially the farmers who work under the hot sun. In order to address this issue, WHO recently lowered the fluoride standard for drinking water for tropical countries from $1 \mathrm{ppm}$ to $0.5 \mathrm{ppm}^{14}$. 
A farmer drinking 3 litres of water from a water source containing $2 \mathrm{ppm}$ fluoride would ingest $6 \mathrm{mg}$ of fluoride a day from drinking water alone. When the intake of aluminofluoride complexes is taken into account, this intake can rise to a quite unhealthy level of around $20 \mathrm{mg}$ per day. This computation is based on the food ingested by an average person where cooking is assumed to be done in sub-standard aluminium pots.

There is considerable debate on the chronic toxicity of fluoride resulting in end stage kidney failure of healthy people. Leaching of heavy metals such as aluminium and lead, under high fluoride stress represents a new way for the entry of toxic heavy metals into the body and the formation of complex fluorides provides a pathway for the chemical amplification of toxins such as fluoride. While fluoride alone may not affect the kidney, along with aluminium it can cause a profound influence on the kidneys of healthy people.

\section{Acknowledgement}

Authors wish to thank Prof. Kenneth Haller at the Suranaree Insititute of Technology, Thailand for help to obtain X-ray fluorescence data. Thanks are also due to Dr. Asoka Katumuluwa at the Maryland Department of Health and Mental Hygiene for the ICP data on aluminium pots. We also thank Dr. Tilak Abyesekera and Dr. Wasantha Dissanayake for many useful discussions. Financial assistance from the Water Supply and Drainage Board of Sri Lanka is gratefully acknowledged.

\section{References}

1. Abeysekera T., Athuraliya T.N.C. \& Amarasinghe P.H. (2003). Chronic renal failure: towards understanding the current trend. Proceeding of Academic Sessions, Vol 4, p 53. Kandy Society of Medicine, Post Graduate Medical Centre, Kandy.

2. Dharmagunawardhane H.A. \& Dissanayake C.B. (1993). Fluoride problemsc in Sri Lanka. Environmental Management and Health 4(2): 9-16.
3. Jankauskas J. (1974). Effects of fluoride on kidney: a review. Fluoride 7(2): 93-105.

4. Lantz O., Jouvin M.H., De Vernejoul M.C. \& Drunet P. (1987). Fluoride-induced chronic renal failure. American Journal of Kidney Diseases 10(22): 36-39.

5. Partane S. (2002). Inhibition of human renal acid phosphotases by nephrotoxic micromolar concentrations of fluoride. Experimental Toxicology \& Pathology 54(3): 231-237.

6. Bi S. (1996). A model describing the complexing effect on the leaching of aluminium from cooking utensils. Environmental Pollution 92(1): 85-89.

7. Rao J.K.S. \& Radhakrishnamurthy R. (1990). Aluminium leaching from utensils during cooking and storage. Environment and Ecology 8(1): 146-148.

8. Zolaly A.B.H. (2001). Leaching of aluminium from metallic aluminium utensils. Oxford Research Forum E-Journal 1(3): 19-24.

9. Walton K.C. (1989). Effect of fluoride on the amount of aluminium dissolved by boiling fruit acids. Environmental Pollution 60(3-4): 223-233.

10. Ileperuma O.A., Dharmagunawardhane H.A. \& Herath P. (2005). Dissolution of aluminium and lead from substandard aluminium pots and its possible implications to chronic renal failure. Proceedings of the $11^{\text {th }}$ Asian Chemical Congress, p 150. August 24-26, Seoul, South Korea.

11. Ileperuma O.A., Dharmagunawardhane H.A. \& Herath K.P.R.K. (2004). Chronic renal failure in the Medawachchiya-Padaviya areas: a geo-environmental study. Proceedings of the Peradeniya University Research Sessions. 9: 156.

12. Isaccson R.L., Varner J.K. \& Jensen K.F. (1998). Toxin induced blood vessel inclusions caused by the chronic administration of aluminum and sodium fluoride and their implications for dementia. Fluoride 31(2): 96-99.

13. Gunnar L. \& Sillen A.E.N. (1964). Stability constants of metal ion complexes. In: Special Publication No. 17. p.264. The Chemical Society, London, UK.

14. World Health Organization Expert Committee on Oral Health Status and Fluoride Use (1994). Fluorides and Oral Health, WHO Technical Report Series No 846. World Health Organization, Geneva, Switzerland. 